\title{
Applying Computer Assisted Instruction Technology to Assist Hurdle Running Teaching: An Approach of Physical Education Network Teaching Resources Based on Massive Open Online Course and Flipped Classroom
}

\author{
Huaijin Liu \\ Faculty of P.E., Hunan Institute of Science and Technology, Yueyang, China \\ Email: tyxlhj@126.com
}

How to cite this paper: Liu, H.J. (2019) Applying Computer Assisted Instruction Technology to Assist Hurdle Running Teaching: An Approach of Physical Education Network Teaching Resources Based on Massive Open Online Course and Flipped Classroom. Open Access Library Journal, 6: e5910.

https://doi.org/10.4236/oalib.1105910

Received: November 8, 2019

Accepted: November 19, 2019

Published: November 22, 2019

Copyright $\odot 2019$ by author(s) and Open Access Library Inc.

This work is licensed under the Creative Commons Attribution International License (CC BY 4.0).

http://creativecommons.org/licenses/by/4.0/

\begin{abstract}
Computer Assisted instruction (CAI) can make up for many shortcomings of traditional teaching by using flipped classroom teaching model based on Massive Open Online Course (MOOC). As an important part of track and field courses in physical education, teachers or coaches in traditional hurdle teaching adopt the way of teacher demonstration and student practice. The teaching means are too simple, and the teaching effect is not good. Based on CAI technology, CAI courseware is designed by using multimedia such as text, picture, animation and video, which makes the teaching process vivid and can overcome the teaching difficulties and highlight the teaching focus. Teaching practice has proved that the application of CAI in hurdle race can effectively improve teaching efficiency and quality.
\end{abstract}

\section{Subject Areas}

Education

\section{Keywords}

CAI in Hurdle Running Teaching, Physical Education,

Network Teaching Resources, MOOC, Flipped Classroom

\section{Introduction}

With the popularization of computers and the development of modern educational technology, computer-aided instruction (CAI) has brought unprecedented 
convenience to the teaching reform, and multimedia courseware for physical education teaching has also emerged as the times require. Computer Aided Instruction (CAI) can make up for many shortcomings of traditional teaching based on PE network teaching resources by using flipped classroom teaching model based on MOOC, such as using multimedia design CAI courseware such as text, picture, animation and video to assist teachers or coaches in demonstrating difficult technical actions in physical education teaching, and using the movement, rotation and freezing of graphics to demonstrate the track and action. The space position of Cheng and various parts of the body is helpful to improve the teaching effect [1]. This research applies CAI to assist Hurdle Race Teaching and training, and develops multimedia CAI courseware with pictures, text, video and animation by means of picture marking, video interception and animation design, which overcomes the difficulties of traditional teaching and greatly improves teaching efficiency and quality.

\section{The Bottleneck of Traditional Hurdle Teaching}

Hurdle race is a highly technical and complex track and field event, which integrates speed, agility and flexibility. It requires students to cross the hurdles continuously in a short time while keeping fast running. It requires students' speed, strength, flexibility, agility, endurance and other qualities as well as overall coordination and space-time sense [2]. In traditional hurdle teaching and training, teachers usually use body demonstration to teach and train. Teachers need to have high skill level and teaching demonstration ability; otherwise it is difficult to standardize the movement. "Sports does not provide for the aged". With the growth of age, it is difficult for the physical shape, physical quality and demonstration ability of PE teachers to continue to adapt to the requirements of technical demonstration. For this reason, teachers usually repeat demonstration or play teaching CD-ROM. Although this usual practice is simple and intuitive in microscopical teaching of motion technology, the repeatability of action is poor, and the teaching efficiency is reduced when teachers repeat demonstration [3]. As we all known that the action of hurdles display is short and fleeting. It is difficult to analyze the motion technology accurately and quantitatively from the micro level, Computer-aided instruction (CAI) can make up for many shortcomings of traditional teaching by using flipped classroom teaching model based on MOOC, when playing CD-ROM on PC or reviewing video on line, the teaching effect will be affected.

\section{Application of CAI in Hurdle Running Teaching}

\subsection{Use Hurdle Pictures to Show Teaching Details}

In the teaching of physical education, appropriate pictures are helpful for students to understand the teaching focus [4]. But the traditional textbooks or courseware, although equipped with illustrations, failed to give full play to the role of pictures. In the design of hurdle CAI courseware, choosing appropriate 
pictures and marking are helpful for students to observe the details of action.

\subsubsection{Typical Picture Selection Can Help Students Understand Key Movements and Stimulate Learning Enthusiasm}

Hurdle running technology can be divided into three parts according to the spatial characteristics of the movement: fast attack hurdle and take-off hurdle, hurdle crossing and landing hurdle. Each part of the body posture has specific movements, such as the angle of ascent and departure when attacking the hurdle, the action of "flat, pull, lift" when taking off the hurdle, the action of "opposite" when crossing the hurdle, the action of "whipping" when dropping the hurdle and so on [5]. Although teachers or coaches can demonstrate each action, sports do not support the elderly, because of age, physical and other reasons, the action is not necessarily very standard, and poor repeatability. The wrong hurdle movement will cause serious consequences. In 2004 Athens Olympic Games, Dukulei, who was next to Liu Xiang, unfortunately fell down on the hurdle, while Liu Xiang won the championship. Through recording the wonderful scenes of the excellent athletes such as Liu Xiang, the typical single frame pictures were extracted by using the commonly used media broadcasting tools software (storm video, super hegemony, etc.) and then used the usual method. Use image processing software (such as Acdsee, Photoshop, etc.) for brightness processing and text annotation. In the courseware, the correct and wrong actions are compared and analysed with the pictures of such sports stars and their standard action demonstrations, which can better demonstrate the action techniques and stimulate students' enthusiasm for learning.

\subsubsection{Fine Image Processing Can Help Students Observe Decomposition Movements and Overcome Teaching Difficulties}

Different versions of track and field textbooks have technical illustrations about hurdle race, and often arrange a group of action sketches together. Although to a certain extent, it helps students understand, but there is no movement in sports, students see a static posture, the understanding of action is imaginable. To this end, scanners or digital cameras are used to scan or take pictures to obtain the picture files of the teaching material's hurdle-crossing technology [6]. Then, the editor function of Acdsee is used to process the picture. Each frame of the picture is separately cut and pasted into PowerPoint with a lasso tool for background transparency processing. The animation effect is designed according to the original action sequence as "appear" or "disappear" in turn, and the playback is carried out. When the courseware is used, the static picture in the original textbook can be changed into the active picture in the courseware, and the students will see the continuous action demonstration. Teachers or coaches can play, pause and return the operation courseware in order to facilitate the presentation and explanation of each decomposition action link.

\subsection{Use Hurdle Running Video to Show Teaching Emphasis}

Physical education pays attention to completing the coordination and coherence 
of the learned movements [7]. Therefore, in the process of teaching, we should not only teach the details of decomposition movements, but also carry out the whole set of exercises. Video broadcast of hurdle race helps students to master the whole hurdle race technology.

\subsubsection{Splendid Video Games Can Stimulate Students' Interest in Learning and Improve Teaching Effect}

Physical education teachers can collect sports videos or movies of contemporary sports stars through materials such as CD-ROM, TV and Internet. Before learning technical actions, students can appreciate the technical actions of stars, feel the beauty of counting actions, and produce the psychological experience of eager to try, so as to stimulate students' interest in learning. This set of hurdle CAI courseware broadcasts the video of our elite athlete Liu Xiang winning the Olympic Games in Athens in 2004 on the cover page. It is edited by the video clipping software Premiere, and takes the national anthem as background music. It fits and controls according to the time axis. The total time is 50 seconds. The video is synthesized into wmv format. When the courseware was broadcasted, the picture of Liu Xiang's hurdle running posture, the name of the courseware and the copyright information were scrolled in the form of film. With the national anthem, hurdle running and the five-star red flag rising, Liu Xiang climbed the top podium and introduced the content of the course in an exciting atmosphere. Stimulate students' patriotism and enthusiasm to learn this course, so that students from the beginning of fear and retreat into admiration and eagerness to try, consciously and actively into the practice of hurdles.

\subsubsection{Appropriate Teaching Videos Can Help Students Learn Technology and Break Through Teaching Difficulties}

Hurdle race uses squatting start technology, focusing on the problem of 8 steps' stride length, rhythm, speed and smooth hurdle crossing. In traditional teaching, teachers or coaches have limited number of demonstration actions, and the quality of action is difficult to ensure consistency [8]. When playing teaching CD-ROM, students cannot grasp the key points well because of the differences in understanding ability. Through visual editing technology, appropriate action fragments are intercepted and compiled with Canopus Edius, a non-linear video editing software, so as to realize the repetition of key action fragments, make full use of students' vision and hearing to form action images, clarify the technical structure and essentials of action, and establish a complete technical concept [4]. It is helpful for students to learn and master hurdle running skills, improve and improve hurdle running skills, and cultivate the ability of continuous hurdle running.

\subsection{Showing Teaching Difficulties with Hurdle Running Animation}

In the traditional hurdle teaching process, teachers usually use body demonstration to demonstrate complete or decomposed technical movements [9]. The 
quality and repeatability of teachers' movements will affect the teaching effect. Through animation design to show the structure, sequence, image and essentials of the action, it can more concretely and intuitively reflect the technical characteristics and difficulties of the action, help students from perceptual knowledge to rational knowledge, so as to better imitate and form the correct action image.

\subsubsection{Image Animation Design Can Help Students Observe Technical Details and Master the Essentials of Action}

In the teaching of hurdle race, we should focus on the development of physical fitness, such as speed, bounce, flexibility, sensitivity and coordination. In the textbooks, we often use words to describe it or insert simple pictures to illustrate it (such as hurdle race technical exercises and specialized flexibility exercises [10]. Teachers in traditional teaching cannot "frame-by-frame" demonstration, using simple animation production software Ulead GIF Animator to design GIF animation, or to convert video AVI file fragments into animation GIF files, both visually and intuitively can help students grasp the essentials of action [11].

\subsubsection{Coherent Animation Production Can Help Students Practice Continuous Movements and Improve the Quality of Movements}

The hurdle race technique requires that running and hurdling be combined naturally and smoothly. Otherwise, students are prone to the phenomenon of not daring to cross hurdles, hitting hurdles or running between hurdles. In traditional teaching, teachers or coaches often demonstrate and explain the main points of action first, and then let students practice. However, some actions (such as pedaling, flying, hurdling and landing) are fleeting. Even if the teacher demonstrates them, it is very difficult for the students to see clearly the actions completed in these moments, and it is also difficult to establish a complete representation of the actions. The slowdown of the teacher also affects the integrity and effect of the actions [12]. Flash software is used to make these key actions into animations and insert them into the courseware. Through interactive control, teachers can combine the characteristics of the actions while demonstrating and explaining them. In some places, they can stop or show them continuously according to the students' grasp of the situation. It is convenient for students to watch the decomposition and combination of the actions and help students to build up the action representation more quickly and comprehensively, so as to better highlight the teaching focus. Help students break through technical difficulties, improve the quality of action, shorten the teaching process and strengthen the teaching effect.

\subsection{Use Hurdle Text to Display Teaching Content}

Text material is editable text and the main carrier of knowledge. Courseware is used for teaching software, so the text used for explaining knowledge points is necessary. The text of hurdle courseware is based on track and field textbook. It is acquired by scanning, identifying or keyboard input, and saved in word, notebook or writing board. 


\subsubsection{The Eye-Catching Title Text Can Help Students Remember the Main Points of Action and Grasp the Teaching Purpose}

The title text plays the role of outline. The title text in hurdle courseware should be concise and concise. It should not only highlight the teaching focus, but also highlight the teaching content. The title text attribute is set to bold, bold, color and other eye-catching effect display. According to the title series, the first-level title text size is set to 32 pounds or more, and the second-level title text is set to 28 pounds or so. The number of words in the title text is consistent, the layout is beautiful and the students can remember it easily.

\subsubsection{Refined Paragraph Texts Can Help Students Understand the Action Principle and Master the Teaching Content}

Paragraph text plays the role of explanation and guidance. Paragraph text in hurdle courseware is simple and concise. It is necessary to explain the relevant terminology concepts as well as the main points of action. According to the textbook, extract the text used to express the essentials of action, exclude unless necessary words, try to retain the core terminology. For example, in the teaching of "whipping" in the movement of starting and striding swing leg, the text explanation of the technical essentials such as swing leg folding, pressing, swing, picking and so on is matched, and then the cross leg lifting and pulling action is repeated, and the text explanation of the technical essentials such as striding, clamping, hooking, inverting and pulling is matched. In this way, teachers can not only avoid publicizing the subject according to the text, but also make it easy for students to understand the action principle and master the teaching content.

\section{CAI-Assisted Hurdle Teaching Experiment}

The CAI hurdle teaching courseware which combines many media elements such as picture, video, animation and text is used in teaching practice after running test and packaging integration. The significance and value of courseware to teaching are evaluated through the experimental results.

\subsection{Objects and Methods of Experiment}

In the physical education classes of 2016, 2017 and 2018 in Hunan Institute of Technology, 40 male and 40 female students were divided into two groups, 20 in each group, which were divided into experimental group and control group. Before the experiment, each group did not learn hurdle race, and the two groups were taught by the same teacher. Except for the experimental group using hurdle CAI courseware to assist teaching, the two groups were consistent in teaching content, hours, sequence, site conditions and evaluation methods.

Considering that the body shape and physical fitness of the subjects will affect the experimental results, the physical shape and physical fitness of the two groups of students were tested before the experiment (see Table 1 and Table 2 ). The results showed that there was no significant difference between the two groups of students $(\mathrm{p}>0.05)$. At the end of the experiment teaching, the 
Table 1. Comparison of basic physical shape and physical fitness between the first two groups in teaching experiment (boys) $(n=60)$.

\begin{tabular}{ccccccc}
\hline & \multicolumn{3}{c}{ Body shape } & \multicolumn{3}{c}{ Physical quality } \\
\cline { 2 - 7 } Group & $\begin{array}{c}\text { Age } \\
(\text { year })\end{array}$ & $\begin{array}{c}\text { Height } \\
(\mathrm{m})\end{array}$ & $\begin{array}{c}\text { Weight } \\
(\mathrm{kg})\end{array}$ & $\begin{array}{c}\text { Standing } \\
\text { long jump } \\
(\mathrm{m})\end{array}$ & $\begin{array}{c}\text { Longitudinal } \\
\text { splitting index } \\
\left({ }^{*}\right)\end{array}$ & $\begin{array}{c}\text { Approach } \\
\text { run height } \\
(\mathrm{m})\end{array}$ \\
\hline $\begin{array}{c}\text { Experience } \\
\text { group }\end{array}$ & $20.3 \pm 0.68$ & $1.76 \pm 0.06$ & $70.6 \pm 6.5$ & $2.66 \pm 0.14$ & $108.26 \pm 1.86$ & $3.08 \pm 0.16$ \\
$\begin{array}{c}\text { Control group } \\
\mathrm{p}\end{array}$ & $20.5 \pm 0.96$ & $1.75 \pm 0.08$ & $70.8 \pm 6.8$ & $2.65 \pm 0.12$ & $106.48 \pm 1.66$ & $3.07 \pm 0.15$ \\
\hline
\end{tabular}

Note: ${ }^{\star}$ Longitudinal splitting index $=$ Leg spacing $/$ Height ${ }^{*} 100$.

Table 2. Comparison of the basic situation of body shape and physical quality between the two groups before the teaching experiment (female students) $(n=60)$.

\begin{tabular}{ccccccc}
\hline & \multicolumn{3}{c}{ Body shape } & \multicolumn{3}{c}{ Physical quality } \\
\cline { 2 - 7 } Group & $\begin{array}{c}\text { Age } \\
(\text { year })\end{array}$ & $\begin{array}{c}\text { Height } \\
(\mathrm{m})\end{array}$ & $\begin{array}{c}\text { Weight } \\
(\mathrm{kg})\end{array}$ & $\begin{array}{c}\text { Standing } \\
\text { long jump } \\
(\mathrm{m})\end{array}$ & $\begin{array}{c}\text { Longitudinal } \\
\text { splitting } \\
\text { index }\left({ }^{*}\right)\end{array}$ & $\begin{array}{c}\text { Approach } \\
\text { run height } \\
(\mathrm{m})\end{array}$ \\
\hline $\begin{array}{c}\text { Experience } \\
\text { group }\end{array}$ & $20.2 \pm 0.79$ & $1.63 \pm 0.05$ & $55.7 \pm 5.8$ & $2.26 \pm 0.16$ & $102.16 \pm 1.22$ & $2.66 \pm 0.13$ \\
$\begin{array}{c}\text { Control group } \\
\mathrm{p}\end{array}$ & $20.3 \pm 0.82$ & $1.65 \pm 0.06$ & $55.8 \pm 5.9$ & $2.28 \pm 0.14$ & $103.41 \pm 1.36$ & $2.70 \pm 0.16$ \\
\hline & $>0.05$ & $>0.05$ & $>0.05$ & $>0.05$ & $>0.05$ & $>0.05$ \\
\hline
\end{tabular}

separation of teaching and examination was used to record the achievements truthfully. The data before and after the experiment were analysed by SPSS 22.0.

\subsection{Experimental Results and Analysis}

After the experiment teaching, two track and field teachers who have been teaching for many years and have excellent skills are required to make strict technical assessment, standard-reaching assessment and theoretical examination (see $\mathrm{Ta}$ ble 3).

From Table 3, it can be seen that there is a significant difference in hurdle race skill evaluation between the two groups after the end of teaching $(\mathrm{p}<0.05)$, indicating that the use of multimedia courseware to assist teaching is more conducive to improving students' technical skills. There was no significant difference ( $p>0.05)$ in the achievement of the standard assessment. It showed that the sports performance of each student had improved no matter using traditional teaching or multimedia courseware, which was related to the comprehensive improvement of many indicators (physical quality, technical and tactical quality, psychological quality and physiological quality). There is a significant difference in the results of theoretical knowledge assessment $(\mathrm{p}<0.05)$. It shows that CAI courseware developed by the combination of various media elements can stimulate students' interest in learning and enhance the teaching effect [13]. 
Table 3. Comparisons of two groups of technical assessment, standard-attaining assessment and theoretical examination after teaching experiment $(n=120)$.

\begin{tabular}{cccc}
\hline Group & $\begin{array}{c}\text { Technical } \\
\text { assessment }\end{array}$ & $\begin{array}{c}\text { Evaluation of } \\
\text { compliance }\end{array}$ & $\begin{array}{c}\text { Theoretical } \\
\text { examination }\end{array}$ \\
\hline Experience group & $86.16 \pm 6.21$ & $8.96 \pm 0.35$ & $95.65 \pm 8.55$ \\
Control group & $82.28 \pm 7.32$ & $8.97 \pm 0.34$ & $92.38 \pm 9.46$ \\
$\mathrm{p}$ & $<0.05$ & $>0.05$ & $<0.05$ \\
\hline
\end{tabular}

\section{Conclusions}

1) In the teaching process of hurdle race, the CAI courseware developed by combining various media elements has higher practical value by using flipped classroom teaching model based on MOOC. It makes students' understanding of hurdle race technology more clear and intuitive, stimulates students' interest in learning, and improves the teaching effect.

2) The CAI courseware of hurdle race developed by combining various media elements can overcome the limitations of traditional teaching by using flipped classroom teaching model based on MOOC, reduce the difficulty of hurdle race teaching, and improve the teaching efficiency and quality.

3) The CAI courseware of hurdle race, which combines various media materials by using flipped classroom teaching model based on MOOC, has shortened the distance between students' theoretical study and practical practice, and is helpful for students to grasp hurdle technical movements quickly and accurately and to grasp hurdle technical principles firmly and thoroughly.

\section{Acknowledgements}

This study was sponsored by the scientific research project of General Project of Hunan Philosophy and Social Science Foundation Program "Research on Co-construction and Sharing Model and Mechanism Innovation of Digital Teaching Resources of PE Courses in Universities and Colleges under the Background of MOOC" (16YBA181), Provincial Social Sciences Achievement Review Committee "Research on the Construction Path and Mechanism Innovation of College PE Course Network Teaching Resources Based on Cloud Computing" (XSP18YBC141). General Project of Hunan Philosophy and Social Science Foundation Program "Research on the development bottleneck and optimization path of College PE Network Teaching Resources Based on Cloud Computing" (18YBA210), Hunan Provincial Education Department "Research on the Improvement of College PE Teachers' Informatization Teaching Ability under TPCK Framework" (18C0629), The research project of teaching reform in Colleges and universities in Hunan Province "The construction and practice of the sharing mode of high quality network course resources of PE in Colleges and Universities Based on O2O" (Xiangjiaotong [2019] No. 291: 617), the research project of teaching reform in Colleges and universities in Hunan Province "Research and Practice on the mechanism of co-construction and sharing of PE network course resources in local 
colleges and Universities" (Xiangiiaotong [2017] No. 452:319), Yueyang social science research project "Research on the system and mechanism of digital teaching resources co construction and sharing of PE curriculum in primary and secondary schools in Yueyang" (2019y33).

\section{Conflicts of Interest}

The author declares no conflicts of interest regarding the publication of this paper.

\section{References}

[1] Xu, X.G. and Xie, L.H. (2005) Making and Application of Sports Multimedia Courseware. Guangxi Normal University Press, Nanning, 13.

[2] Lan, B.S. (2004) Analysis of the Factors Affecting the Performance of Hurdles in China. China Sports Science and Technology, 2, 7-10, 62.

[3] Li, H.J. (2008) Track and Field. 2nd Edition, Higher Education Press, Beijing, 150.

[4] Xu, W. and Wang, M. (2012) Application of Multimedia Courseware in Physical Education. Journal of Harbin Institute of Physical Education, 1, 70-72, 76.

[5] Ma, Y.C. (2013) The Application of Multimedia CAI Technology in College Physical Education. Contemporary Sports Science and Technology, 3, 107-109.

[6] Shu, Y. and Zhang, Y.B. (2018) A Review of Hurdling Techniques. Youth Sports, 6, 124-125.

[7] Tang, P. (2018) Analysis of the Technical Characteristics of the Leg Lifting in Hurdle Race. Hubei Sports Science and Technology, 37, 714-716.

[8] Zeng, X. (2018) Common Problems and Teaching Strategies of Hurdle Race. Chinese School Physical Education, 3, 44.

[9] Hu, S.Q. and Fu, Y. (2017) Teaching and Training Methods and Problems of Running Hurdle Technique. Contemporary Sports Science and Technology, 7, 58-60.

[10] Wang, W.B. and Wang, L. (2017) Influencing Factors and Development Countermeasures of Hurdle Teaching. Contemporary Sports Science and Technology, 7, 146-148.

[11] Huang, C. (2014) Research on CAI Teaching Reform of Physical Education in Colleges and Universities. Science and Education Collection (Later Periodicals), 6, 97-99.

[12] Zhang, L.P. (2013) The Application of Multimedia CAI Technology in the Teaching of Sports Technology. Contemporary Sports Science and Technology, 3, 36-38.

[13] Liu, H.J., Li, Y.B. and Tang, J. (2019) Construction and Application of Digital Teaching Resources in Regional Basic Education-Taking Physical Education Courses as an Example. Creative Education, 6, 1192-1204.

https://doi.org/10.4236/ce.2019.106090 